\title{
Structural upgrade of deficient Unreinforced Masonry structures using Ultra High Performance Fibre Reinforced Concrete
}

\author{
Andreas Lampropoulos, Ahmad Tasji, Ourania Tsioulou
}

School of Environment and Technology, University of Brighton, UK

Contact: a.lampropoulos@brighton.ac.uk

\begin{abstract}
The structural upgrade of substandard Unreinforced Masonry (URM) is an urgent need worldwide and especially in earthquake prone areas and in low and middle income countries. The majority of the existing URM buildings in these areas have not been designed to resist seismic action, and in many cases, substandard materials have been used, therefore the structural strengthening of these structures is essential. The strengthening of existing low strength masonry is a quite challenging task since the effectiveness of the external application of high strength materials (e.g. Fibre Reinforced Polymers) is limited due to the poor connection between the new materials and the existing substrate which leads to de-bonding and premature failure of the strengthened structures. In this study, a novel strengthening technique has been examined using Ultra High Performance Fibre Reinforcement Concrete (UHPFRC) layers in addition to partial replacement of the existing mortar with UHPFRC. Experimental investigation has been conducted on brick walls constructed using low strength bricks. UHPFFRC layers with various thicknesses with and without UHPFRC at the joints have been applied to the URM walls and flexural out-of-plane tests have been conducted. The experimental results demonstrate that the proposed technique can considerably improve the ultimate load and the ductility of the URM walls. Also, the proposed technique offers improved UHPFRC-to-URM interface conditions.
\end{abstract}

Keywords: UHPFRC, masonry, strengthening, out-of-plane.

\section{Introduction}

Unreinforced Masonry (URM) is one of the most commonly used construction types in many earthquake prone areas worldwide. However, the majority of the existing URM structures are prone to earthquakes due to the low mechanical properties of the material and due to the lack of implementation of seismic code provisions. In addition to this, many of these structures in low and middle income countries have been constructed using sub-standard materials and inappropriate techniques and therefore they are of very high seismic risk. The strengthening of URM structures worldwide and especially in low and middle income and in heritage areas is becoming an increasingly alarming research topic and an urgent need for the protection of these areas. The use of novel high performance concrete for the structural upgrade of the URM is an area which is currently under investigation. External application of Fibre Reinforced Polymers (FRPs) has been studied in the last few years [1-4] and it has been proved that the superior tensile strength characteristics of the FRPs can be beneficial for the improvement of the mechanical 
characteristics of URM. However, the connection between the existing URM and the FRPs is weak and premature de-bonding and failure normally occurs.

In the last decade, the development of cementitious high performance materials has been extensively studied and novel concepts and applications have been proposed. The use of Ultra High Performance Fibre Reinforced Concrete (UHPFRC) has been proved to be quite efficient for the flexural and shear strengthening of existing Reinforced Concrete (RC) elements [5, 6]. The application of UHPFRC for the structural strengthening of URM walls has been examined numerically $[7,8]$, and the efficiency for both inplane and out-of-plane loading conditions has been highlighted. However, the experimental validation of this application has not been presented in any previous studies.

In this paper, low strength bricks were used to simulate substandard materials normally used in low and middle income countries, and the strengthening of URM using UHPFRC layers with various thicknesses was examined. Out-of-plane tests were conducted in all the examined specimens and the experimental results are presented in the following sections.

\section{Experimental investigation and specimens preparation}

In this section, the geometry and the dimensions of the examined specimens are presented alongside with the material properties and description of the UHPFRC preparation.

\subsection{Description of the examined specimens and material properties of the URM}

In this study, low strength aerated concrete bricks have been used in order to simulate substandard bricks used in low and middle income countries. The dimensions of the bricks are $65 \mathrm{~mm} \times 100 \mathrm{~mm}$ $x 215 \mathrm{~mm}$ and their compressive strength was found equal to $3.57 \mathrm{MPa}$. Eight specimens were examined in total; two URM specimens (URM-1, URM-2), two specimens strengthened with $14 \mathrm{~mm}$ thick UHPFRC layer (UHPFRC_14mm-1,
UHPFRC_14mm-2), two specimens strengthened with $22 \mathrm{~mm}$ thick UHPFRC layer (UHPFRC_22mm1, UHPFRC_22mm-2), and two specimens strengthened with $30 \mathrm{~mm}$ thick UHPFRC layer (UHPFRC_30mm-1, UHPFRC_30mm-2).

The dimensions of the URM specimens together with one of the examined samples prior to testing are presented in Figure 1.
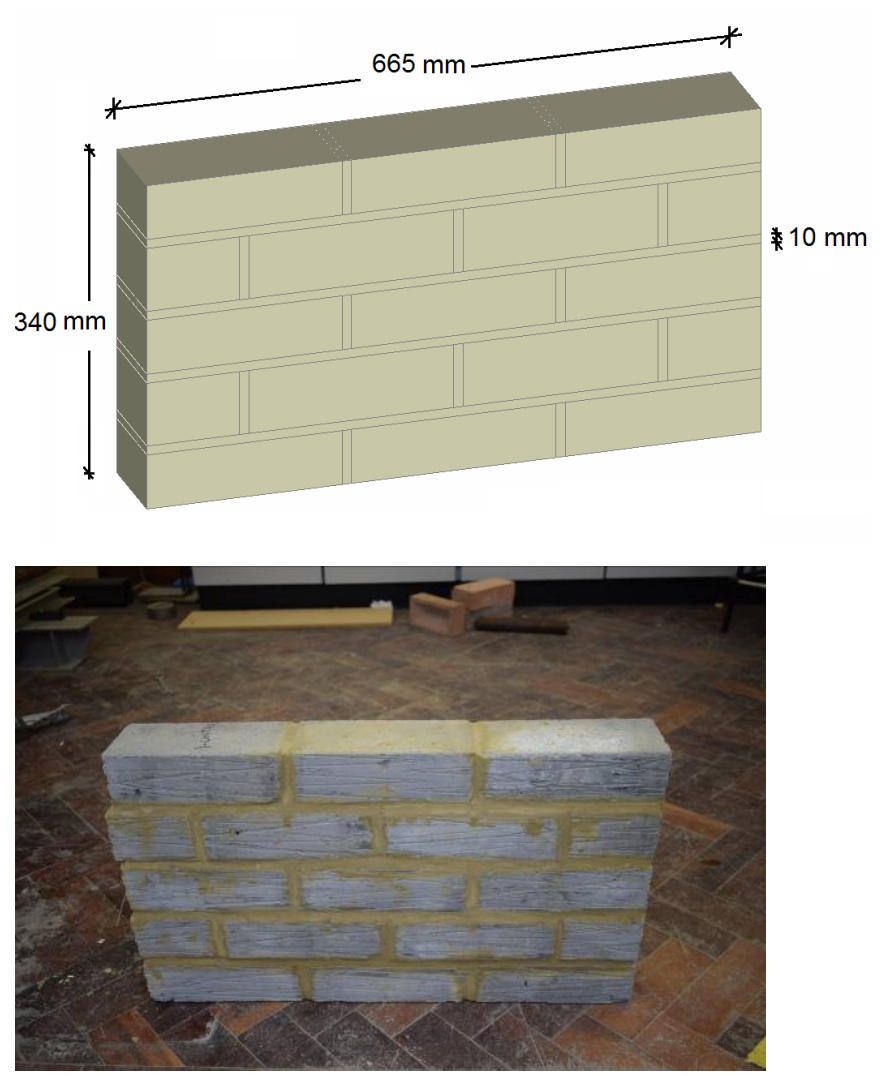

Figure 1. URM walls

For the mortar used in the examined specimens, cement, lime and sand with by volume ratio 1:1/3:3 was used with water to cement by weight ratio equal to 0.32 representing standard mortar used in masonry walls. The compressive strength of this mortar was found equal to $21.24 \mathrm{MPa}$ after conducting standard compressive cube tests.

\subsection{UHPFRC preparation and strengthening of the URM}

For the strengthening of the URM specimens, UHPFRC layers with three different thicknesses $(14 \mathrm{~mm}, 22 \mathrm{~mm}$, and $30 \mathrm{~mm})$ were cast in contact with the existing specimens (Figure 2). 


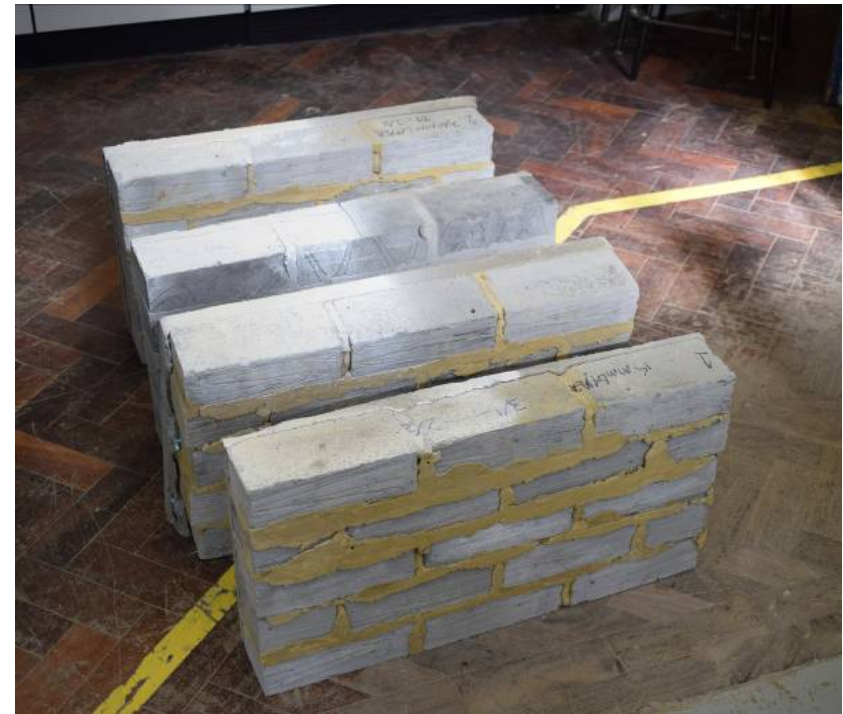

Figure 2. Strengthened specimens with UHPFRC layers with various thicknesses

The mix design of the UHPFRC used in this study is presented in Table 1.

Table 1. UHPFC mix design

\begin{tabular}{cc}
\hline Material & $\begin{array}{c}\text { Mix proportions } \\
\left(\mathrm{kg} / \mathrm{m}^{3}\right)\end{array}$ \\
\hline Cement & 657 \\
GGBS & 418 \\
Silica fume & 119 \\
Silica Sand & 1051 \\
$\begin{array}{c}\text { Superplasti } \\
\text { cizers }\end{array}$ & 59 \\
Water & 185 \\
\hline $\begin{array}{c}\text { Steel fibers } \\
(3 \%)\end{array}$ & 235.5 \\
\hline
\end{tabular}

Silica sand with maximum particle size of $500 \mu \mathrm{m}$ was initially mixed together with dry silica fume, Ground Granulated Blast Furnace Slag (GGBS), and cement (32.5R). After the mixing of the dry materials, water and polycarboxylate superplasticizer were added to the mix followed by gradual addition of straight steel fibres with $6 \mathrm{~mm}$ length, $0.16 \mathrm{~mm}$ diameter, and $3000 \mathrm{MPa}$ tensile strength. The specimens were cured under normal conditions for two months after the casting of the UHPFRC layers and then the specimens were tested under out-of-plane loading as presented in Figure 3a. Span length equal to
$520 \mathrm{~mm}$ was selected and tests were conducted under displacement control with a loading rate $0.1 \mathrm{~mm} / \mathrm{min}$. The load versus displacement was recorded during the tests, while Digital Image Correlation System was also used to monitor the strains and the cracks at the interface between the UHPFRC and the URM in all the strengthened units (Figure $3 b$ ).

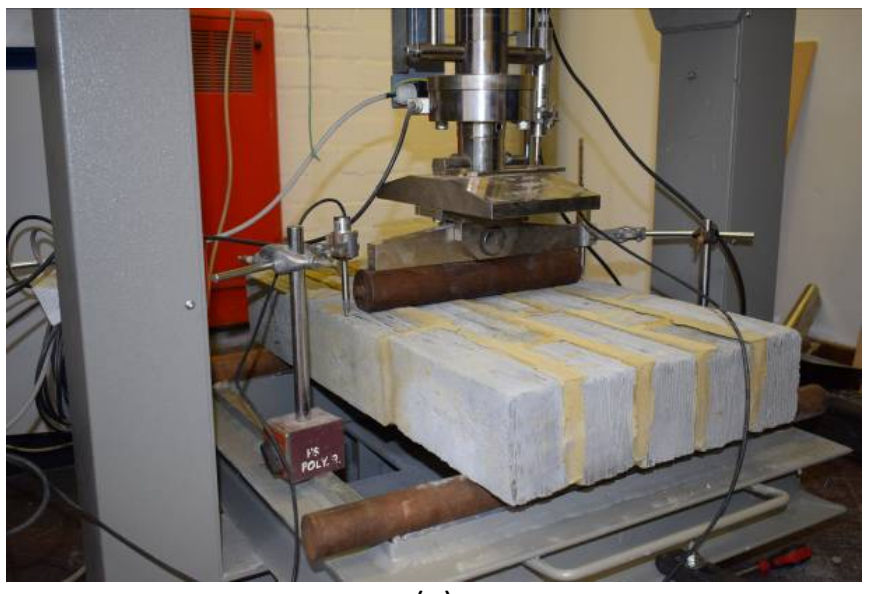

(a)

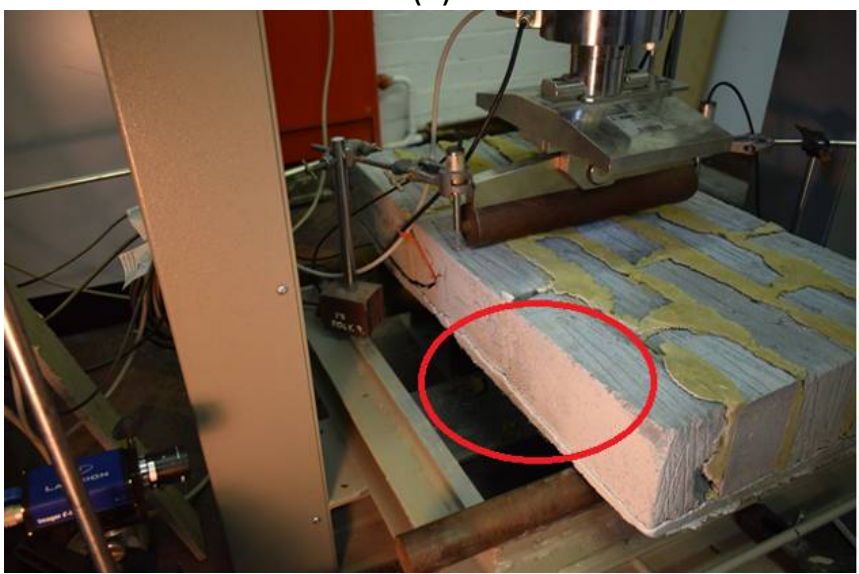

(b)

Figure 3. a) Testing setup and b) Digital Image Correlation setup for the monitoring of the interface

Cubes with $100 \mathrm{~mm}$ side and dog-bone specimens with $14 \mathrm{~mm} \times 20 \mathrm{~mm}$ cross section were also cast and tested at the same age in order to obtain compressive strength and tensile stress-strain characteristics of the UHPFRC. The cube compressive strength was found equal to $116 \mathrm{MPa}$ while the maximum tensile strength was found almost equal to $4 \mathrm{MPa}$. The results of the out-ofplane testing are presented in the following section (section 3 ). 


\section{Results and discussion}

\subsection{Experimental results}

The load versus mid-span displacement results of all the examined specimens are presented in Figure 4. Also, it should be mentioned that error was induced in the initial displacement recordings of one of the UHPFRC_14mm and one of the UHPFRC_22mm specimens, due to undesirable displacements at the supports, and these were corrected using the respective recordings of the other identical specimens of each pair.

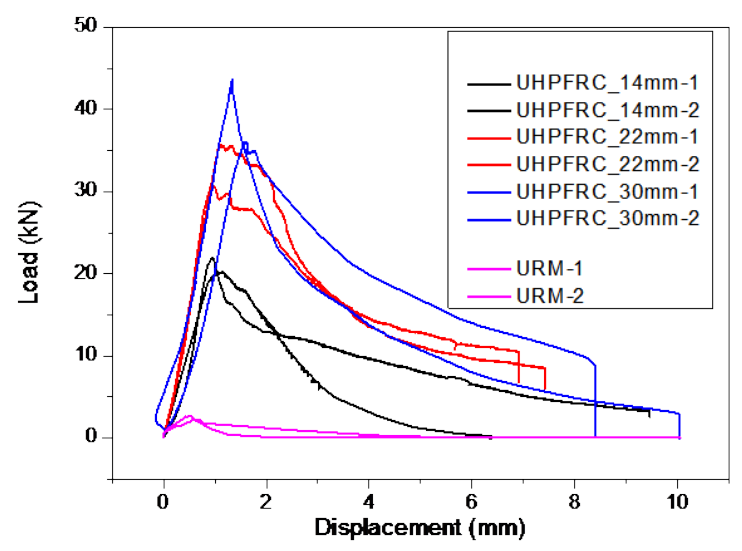

Figure 4. Load versus mid-span displacement results for the out-of-plane tests

The results of Figure 4 indicate that maximum load is considerably increased by the addition of UHPFRC layers and the maximum load is increased as the thickness of the layer is increased, as expected. In addition to the maximum load, the area under the load-displacement results and subsequently the energy absorption of the strengthened specimens is significantly enhanced. This is attributed to the superior stress strain characteristics of the UHPFRC and the bridging effect of the fibres which is one of the main characteristics of UHPFRC. The results of Figure 4 have been used to calculate the average loaddisplacement results of the two identical specimens of each type which are illustrated in Figure 5.

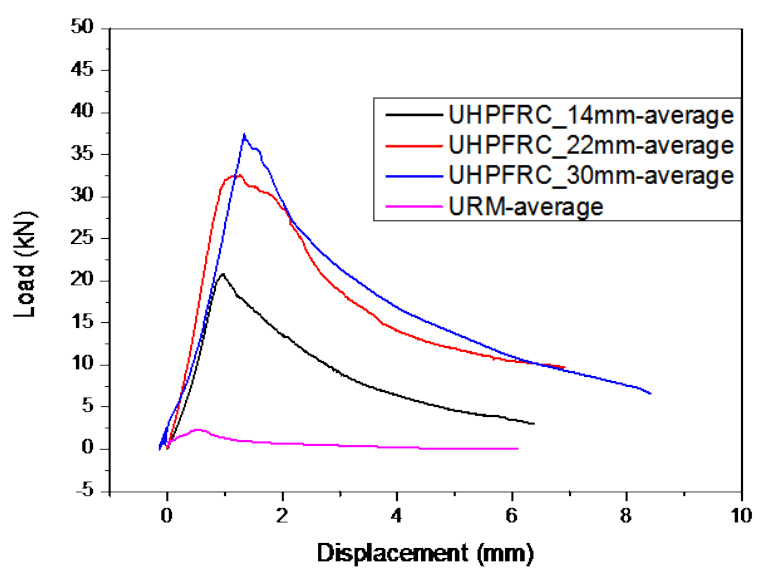

Figure 5. Average load versus mid-span displacement results for the out-ofplane tests

Based on the results of Figure 5, the maximum average load of URM was calculated to be equal to $2.37 \mathrm{kN}$, while for the strengthened specimens the respective maximum load value was significantly higher and equal to $20.86 \mathrm{kN}$ for UHPFRC_14mm, $32.56 \mathrm{kN}$ for UHPFRC_22 $\mathrm{mm}$, and $37.44 \mathrm{kN}$ for UHPFRC_30 mm.

Regarding the bond between the bricks and the UHPFRC layer, very good connection between the two materials was observed during the testing. It is important to highlight that almost perfect bond between the two materials was observed until the point when cracks were initiated in the outermost tensile side of the bricks which were then progressed to the UHPFRC-to-bricks interface and then to the UHPFRC layer. It should also be mentioned that the cracks at the UHPFRC appeared at a very late loading stage which is attributed to the superior ductility of the UHPFRC layer.

Typical failure modes of all the four different types of specimens are presented in Figure 6 . The failure of URM (Figure 6a) occurred in a brittle way, as expected, and the specimen was completely damaged at a low load value. In case of strengthened specimens, the failure was initiated at the bricks followed by interface failure, and then cracks were developed at the UHPFRC layer. 


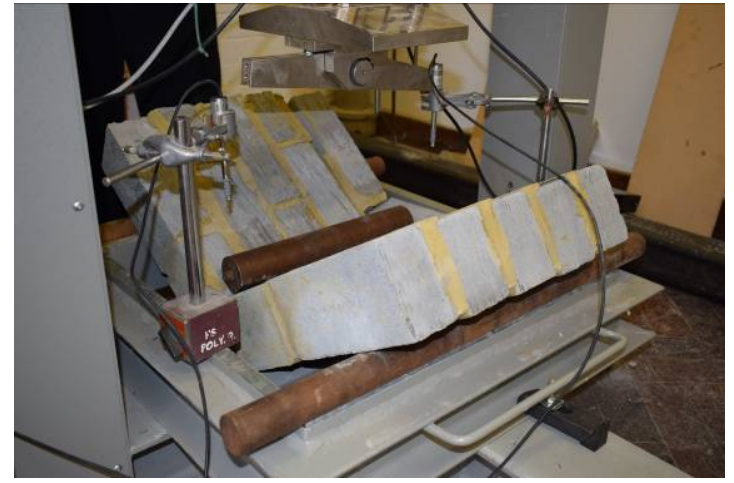

(a)

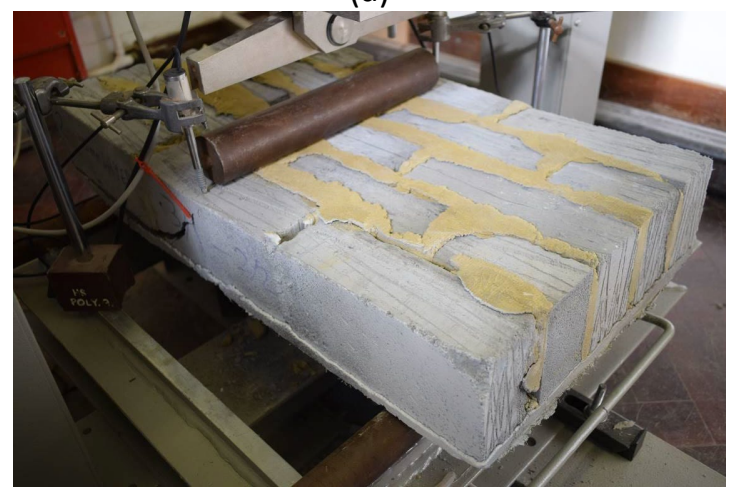

(b)

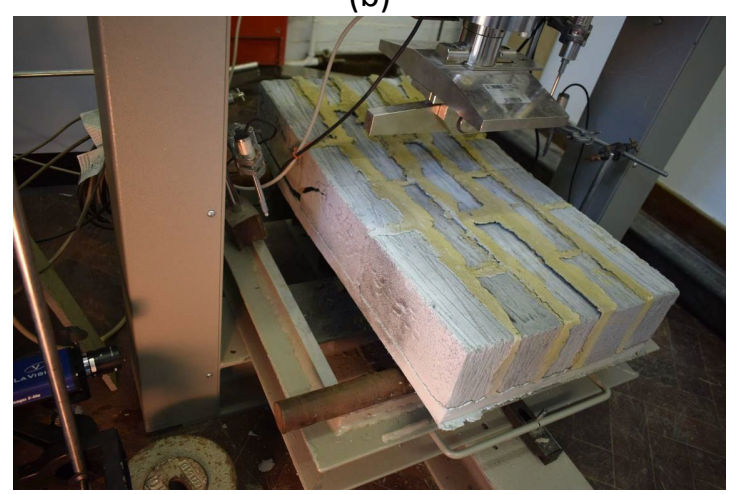

(c)

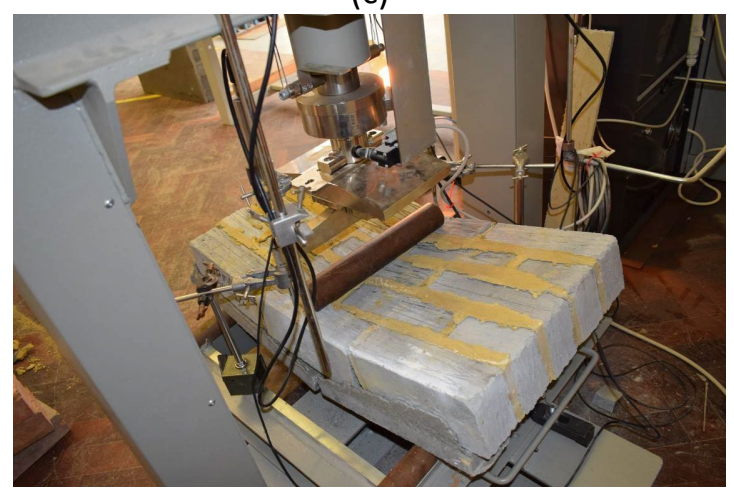

(d)

Figure 6. Typical failure modes of a) URM, b) UHPFRC_14mm, UHPFRC_22mm, and c) UHPFRC_30mm specimens
In case of specimens UHPFRC_14mm and UHPFRC_22mm (Figure $6 \mathrm{~b}$ and $6 \mathrm{c}$ ) there was not significant crack localization at the UHPFRC layer and most of the cracks appeared at the bricks and at the interface, while in case of UHPFRC_ $30 \mathrm{~mm}$ significant crack opening was observed at the middle of the span of the UHPFRC in addition to significant damage of the bricks.

It is important to mention that in all the examined strengthened specimens, almost perfect bond was observed at the UHPFRC-to-bricks interface up to the maximum load of the load deflection results, and any slips and cracks occurred at the softening branch of the load deflection curve.

In depth investigation of the interface behavior was performed using the Digital Image Correlation system which was used in this study to monitor the interface (Figure $3 \mathrm{~b}$ ).

The shear strain was calculated for one of each type of strengthened specimens (UHPFRC_14mm, UHPFRC_22mm, and UHPFRC_30mm) and indicative results for the shear strain distribution at the middle and at the end of the imposed midspan displacement (Figure 4) are presented in Figure 7.

The results of Figure 7 indicate that in case of specimen strengthened with $14 \mathrm{~mm}$ thick UHPFRC layer (UHPFRC_14mm) there are high shear strain values and slip at the interface not only at the end of the loading history (Figure $7 \mathrm{~b}$ ) but also for loading stage at the middle of the loaddisplacement history (Figure 7a). However even in this case, the high shear strain and interface slip values occurred after the maximum load value.

The respective shear strain distributions for UHPFRC_22mm and UHPFRC_30 $\mathrm{mm}$ specimens are presented in Figure 8 and Figure 9. Based on the results for these two types of strengthened specimens, there are not high shear strain values for loading stage at the middle of the maximum imposed displacement when $22 \mathrm{~mm}$ and $30 \mathrm{~mm}$ thick UHPFRC layers were used. This indicates very good interface connection even for a quite late loading stage which corresponds to the softening branch of the load-displacement graph where significant damage has occurred to the bricks. 


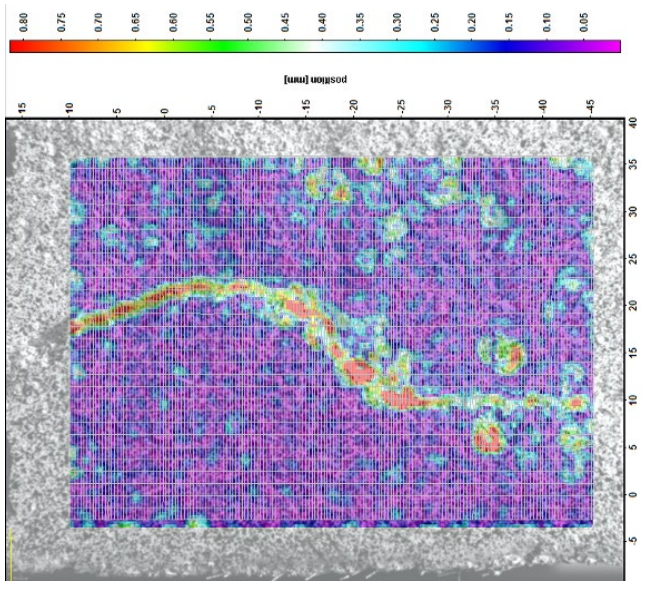

(a)

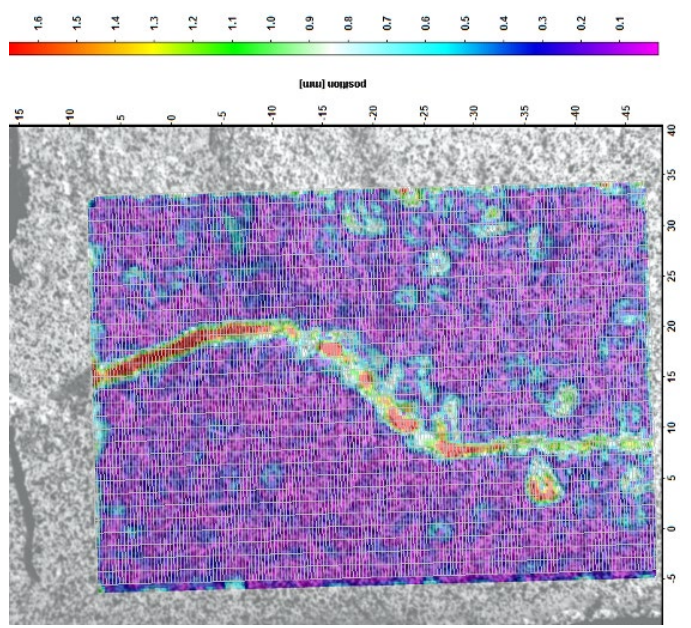

(b)

Figure 7. Shear strain distribution for lading stage a) at the middle, and b) at the maximum imposed displacement value for UHPFRC_14mm specimen

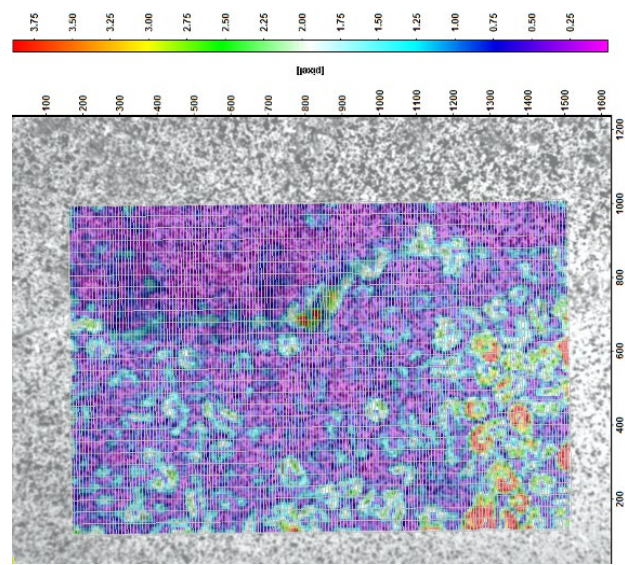

(a)

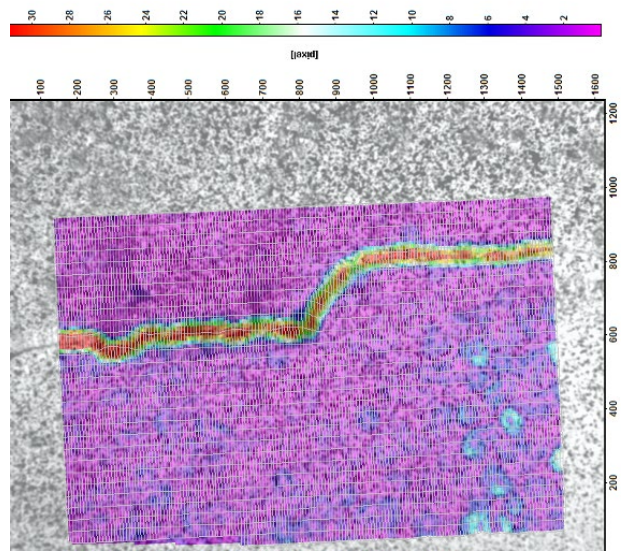

(b)

Figure 8. Shear strain distribution for lading stage a) at the middle, and b) at the maximum imposed displacement value for UHPFRC_22mm specimen

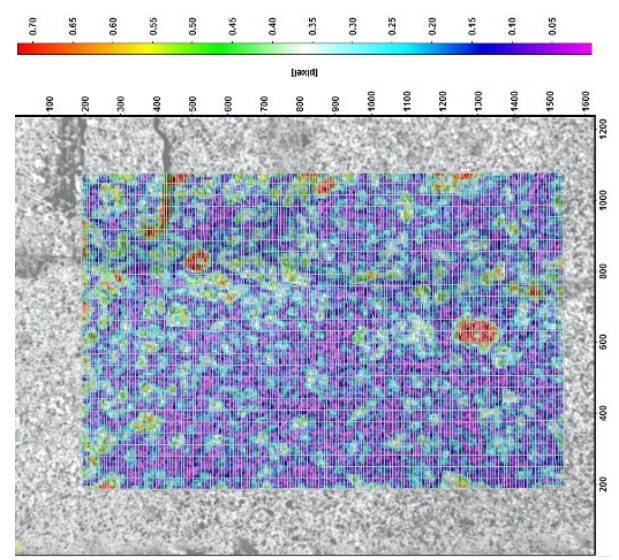

(a)

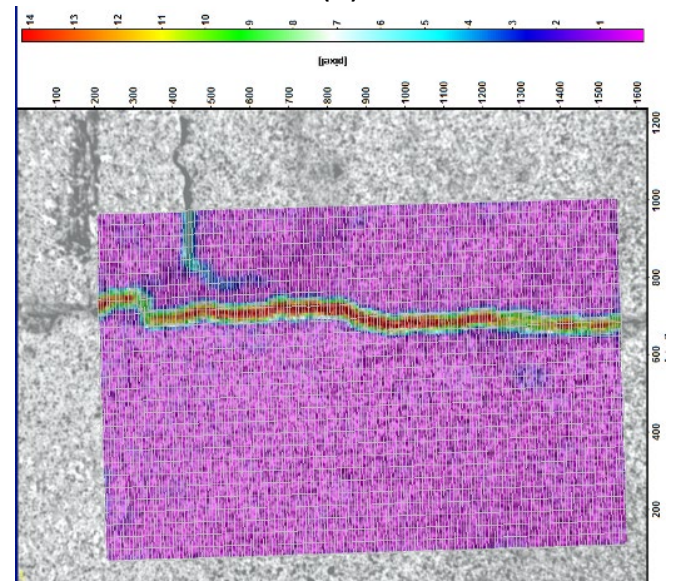

(b)

Figure 9. Shear strain distribution for lading stage a) at the middle, and b) at the maximum imposed displacement value for UHPFRC_30mm specimen 


\subsection{Analytical calculations}

A simplified analytical method was also examined to calculate the contribution of the additional UHPFRC layer to the maximum load capacity of the strengthened specimens. Cross section analysis was applied using uniform maximum tensile stress value at the UHPFRC layer equal to $4 \mathrm{MPa}$, value observed experimentally from the direct (dog-bone) tensile tests. The internal force $\mathrm{F}_{S_{-} \text {UHPFRC }}$ was then calculated by multiplying the maximum stress value by the thickness and the width of the layer. The moment increment was then simplified calculated as the internal force

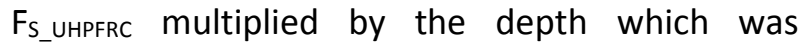
considered equal to the sum of the depth of the brick and half of the depth of the layer (Figure 10).

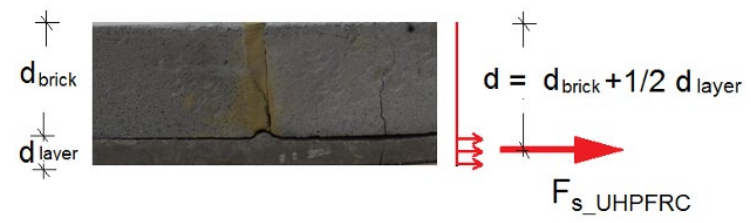

Figure 10. Cross section stresses and internal force contribution of the UHPFRC layer

This simplified procedure was used to calculate the maximum load increment and the ultimate load of all the three types of strengthened walls. The analytical maximum load values were found equal to $18.04 \mathrm{kN}$ for UHPFRC_14mm, $27.92 \mathrm{kN}$ for UHPFRC_22mm, and $38.46 \mathrm{kN}$ for UHPFRC_ $30 \mathrm{~mm}$.

The comparisons between the calculated values and the values obtained experimentally are illustrated in Figure 11.

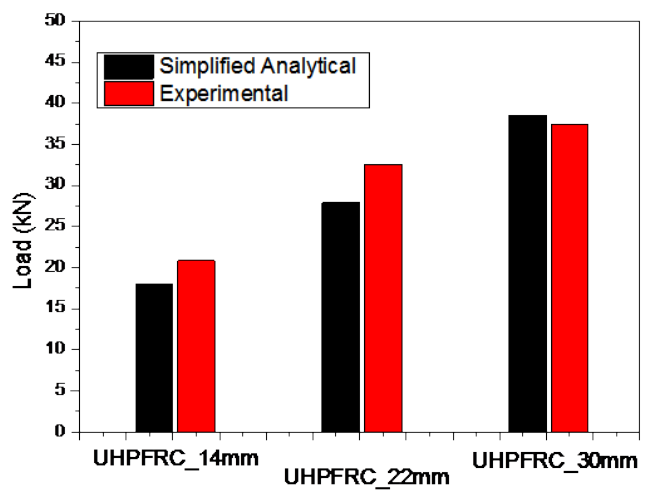

Figure 11. Comparisons between the experimental and the analytical maximum load values
The results of Figure 11 indicate that the maximum load values calculated with the simplified analytical method are in very good agreement with the respective experimental results. As discussed earlier in section 3.1, perfect bond was observed at the interface between the UHPFRC and the URM for loading stage up to the maximum load value and therefore the simplified analytical method presented here, considering perfect connection between the two materials, is appropriate.

\section{Conclusions and recommendations}

In this paper, experimental investigation was conducted in order to evaluate the efficiency of the use of additional UHPFRC layers with various thicknesses for the strengthening of low strength URM. In addition to the load-mid span displacement results, the strains at the UHPFRCto-bricks interface were monitored using Digital Image Correlation System and then a simplified analytical approach was used to calculate the maximum load increment of the strengthened specimens.

Based on the results of this study the following conclusions can be drawn:

- The maximum load and the energy absorption of all the examined strengthened specimens were considerably increased by the addition of UHPFRC layers. The strength and ductility enhancement were increased as the thickness of the layer was increased, as expected.

- In case of strengthened specimens, the failure was initiated with cracks at the bricks followed by interface failure, and then cracks were developed at the UHPFRC layer.

- In all the examined specimens perfect bond was observed at the UHPFRC-tobricks interface up to the maximum load value. Then, in the softening branch of the load-displacement graph and after significant damage of the bricks, high shear strains were observed at the 
interface and interface slips and cracks occurred.

- A simplified analytical method was used to predict the maximum load increment by calculating the internal stresses and force contribution of the UHPFRC, and very good agreement with the respective experimental results was observed.

\section{References}

[1] Abrams, D., Smith, T., Lynch J., and Franklin, S. Effectiveness of Rehabilitation on. Seismic Behaviour of Masonry Piers. ASCE Journal of Structural. Enginering. 2007; 133(1), 32-44.

[2] Galati, N., Tumialan, G., and Nanni, A. (2006), Strengthening with FRP bars of URM walls subject to out-of-plane loads. Construction and Building Materials. 2006; 20(1-2): 101-110.

[3] Mosallam, A. Out-of-plane flexural behavior of unreinforced red brick walls strengthened with FRP composites. Composites: Part B. 2007; 38: 559-574.

[4] Roca, P., Araiza, G. Shear response of brick masonry small assemblages strengthened with bonded FRP laminates for in-plane reinforcement. Construction and Building Materials. 2010; 24, 1372-1384.

[5] Lampropoulos, A., Paschalis, S., Tsioulou, O., and Dritsos, S. Strengthening of reinforced concrete beams using ultra high performance fibre reinforced concrete (UHPFRC). Engineering Structures. 2016a; 106: 370-384.

[6] Bastien Masse, M., Brühwiler, E. Contribution of R-UHPFRC Strengthening layers to the shear resistance of $\mathrm{RC}$ elements. Structural Engineering International, 2016; 4: 365-374

[7] Lampropoulos, A., Tsioulou O., Paschalis S., and Dritsos, S. Strengthening of unreinforced masonry structures using Ultra High Performance Fibre Reinforced Concrete (UHPFRC). 19 ${ }^{\text {th }}$ IABSE Congress, Stockholm, Sweden, 2016b.
[8] Lampropoulos, A., Tsioulou O., Paschalis S., and Dritsos, S. Strengthened Unreinforced Masonry (URM) structures with Ultra High Performance Fibre Reinforced (UHPFRC) layers under axial in-plane and horizontal out-of-plane loading. $39^{\text {th }}$ IABSE Symposium, Vancouver, Canada, 2017. 